\title{
Efficacy and safety of ketotifen eye drops in the treatment of seasonal allergic conjunctivitis
}

\author{
M Kidd, S H McKenzie, I Steven, C Cooper, R Lanz, and the Australian Ketotifen Study Group*
}

Br J Ophthalmol 2003;87:1206-1211

Background: Ketotifen blocks histamine $\mathrm{H}_{1}$ receptors, stabilises mast cells, and prevents eosinophil accumulation. These multiple, pharmacological mechanisms provided the rationale for assessing the efficacy and safety of ketotifen $0.025 \%$ eye drops in subjects with seasonal allergic conjunctivitis (SAC) in an environmental setting.

Methods: This was a double masked, randomised, multicentre trial conducted in Australia. Subjects were randomly assigned to ketotifen fumarate $0.025 \%$ ophthalmic solution, placebo (as vehicle), or levocabastine hydrochloride $0.05 \%$ ophthalmic suspension, twice daily in each eye for a 4 week period. Subjects were assessed at follow up (days 5-8) and termination (days 25-31) visits. The primary efficacy variable was the responder rate, based on the subjects' assessment of global efficacy at the follow up visit.

Results: 519 subjects were randomised to treatment. At the follow up visit, the responder rate, based on subjects' assessment of global efficacy, was significantly greater in the ketotifen group $(49.5 \%)$ than in the placebo group (33.0\%) for subjects with a positive diagnostic test for pollen allergy $(p=0.02)$. The investigators' assessment of responder rates also showed that ketotifen was superior to placebo $(p=0.001)$. Ketotifen produced a significantly better outcome than levocabastine $(p<0.05)$ for relief of signs and symptoms of SAC, at both the follow up and the termination visit. The type and frequency of adverse events were similar across treatment groups.

Conclusions: In an environmental setting, ketotifen fumarate $0.025 \%$ ophthalmic solution was well tolerated and effective in reducing the signs and symptoms of SAC, and in preventing their recurrence. Ketotifen consistently showed the best efficacy in comparison with both placebo and levocabastine. These results indicate that ketotifen eye drops are a valuable treatment option for this condition.

$\mathrm{S}$ easonal allergic conjunctivitis (SAC), or hay fever conjunctivitis, is a hypersensitivity reaction to specific airborne allergens, mainly pollens. With an estimated prevalence of approximately $15-20 \%,{ }^{12}$ SAC is the most common form of ocular allergy, affecting adults and children alike. Although serious sequelae as a result of corneal involvement are rare, the distressing signs and symptoms of SAC may cause extreme discomfort. ${ }^{3}$ The range of ocular symptoms varies from itching and redness to swelling, excessive lacrimation, and mucous discharge. ${ }^{23}$

The early allergic response in SAC results from allergen mediated cross linking of pairs of immunoglobulin (Ig) E on the surface of conjunctival mast cells. This leads to mast cell degranulation and release of mediators including histamine, tryptase, leukotrienes, cytokines, and platelet activating factor. ${ }^{45}$ Histamine stimulates nerve endings and dilates the blood vessels, causing itching and redness. Similarly, platelet activating factor dilates the blood vessels and recruits eosinophils to the site, resulting in redness and swelling, and a prolonged allergic response. Because allergen avoidance is generally unachievable in SAC, there is often the need for therapeutic interventions that offer effective and sustained symptomatic relief.

Ketotifen has three independent pharmacological mechanisms that appear to contribute to its anti-allergy effects: inhibition of histamine $\mathrm{H}_{1}$ receptors, mast cell stabilisation, and prevention of eosinophil accumulation. ${ }^{6}$ Ketotifen fumarate (Zaditen/Zaditor, Novartis Ophthalmics), a benzocycloheptathiophene derivative, is a twice daily ophthalmic formulation that has been developed for alleviating the signs and symptoms of SAC.

The purpose of this study was to compare the efficacy and safety of ketotifen fumarate $0.025 \%$ ophthalmic solution with placebo and levocabastine $0.05 \%$ ophthalmic suspension (Livostin), a histamine $\mathrm{H}_{1}$ receptor antagonist, in an environmental setting.

\section{SUBJECTS AND METHODS}

\section{Selection of study population}

Subjects were recruited through a media campaign. Subjects eligible for inclusion were males or females aged 12 years or older and suffering from SAC, which was diagnosed on the basis of their history, a positive diagnostic radio-allergosorbent test (RAST), the presence of moderate to severe ocular itching, and at least one of the following bilateral signs and symptoms of at least moderate severity: conjunctival hyperaemia, conjunctival chemosis, eyelid swelling, or tearing.

Subjects with the following conditions were excluded: presence of any other form of allergic conjunctivitis; infective conjunctivitis; history of dry eye; presence of any ocular condition which could have affected trial variables or any condition requiring disallowed treatment. Subjects who had ocular surgery within 3 months of the study, or had systemic or ocular corticosteroids, or mast cell stabilisers within 2 weeks of randomisation, or any other ophthalmic medication within 3 days of randomisation were also excluded from the study. Concomitant systemic treatments for allergy and any local ocular treatments (including artificial tears or normal saline) other than the trial medication were not permitted during the study. Topical treatments (nasal drops/sprays/ inhalers, oral inhalers) for allergic rhinitis and/or symptomatic asthma were allowed from the follow up visit (days 58 ) to the study termination visit (days 25-31).

The study protocol, information sheets, consent forms, and the media releases for the subject recruitment campaign were reviewed and approved by the ethics committees of the Royal Australian College of General Practitioners, the Central Sydney Area Health Service, the ACT Department of Health and Community Care, and the University of Sydney. The study was conducted according to good clinical practice 
standards, and written informed consent was obtained from all subjects before the start of any study related procedures.

\section{Study design}

This was a double masked, balanced randomised, parallel group, placebo controlled multicentre trial using levocabastine as an active control. The study was conducted by general medical practitioners with the support of consultant ophthalmologists at seven regional centres in Australia.

Eligible subjects were randomised (RANCODE version 3.6, IDV Datenanalyse und Vesuchsplanung, Gauting, Germany) to one of the three treatment groups: ketotifen fumarate $0.025 \%$ ophthalmic solution, placebo (vehicle ophthalmic solution), or levocabastine $\mathrm{HCl} 0.05 \%$ ophthalmic suspension. Treatment was given twice daily in each eye for 4 weeks. The packaging of all trial medications was identical in appearance.

\section{Outcome measures}

\section{Primary efficacy variable}

The primary efficacy variable was the responder rate, as judged by subjects. Subjects were asked to assess the overall effect of treatment on symptoms using a five point grading scale (Table 1). A score of 0 or 1 (excellent or good efficacythat is, complete or distinct symptom relief) was used to define a responder, and the primary analysis was at the follow up visit, held between days 5 and 8 .

\section{Secondary efficacy variables}

At the follow up visit, investigators also assessed response to treatment. This assessment was based on the effect of treatment on signs and symptoms, and used a five point grading scale that was similar to the one used by subjects (Table 1). Responder rates were also assessed at the termination visit, held between days 25 and 31 .

At each visit, ocular symptoms (itching, tearing) were graded by the subject, ocular signs (redness, eyelid swelling, chemosis) were graded by the investigator, using ordinal grading scales (Table 2). An absent/present assessment was done for mucous discharge. In addition to individual scores, the composite scores for ocular signs and symptoms were calculated. Every day during the study, subjects kept a diary in which they recorded the severity of ocular allergy symptoms. The number of symptom free days, defined as treatment days where ocular allergy symptoms were absent in the subjects' global assessment of symptoms, was calculated from the subjects' diary records.

\section{Tolerability and safety}

Assessment of tolerability was based on adverse event data obtained by the subject volunteering the information and by the physician or the nurse questioning the subject at each visit. Any ocular discomfort was recorded as an adverse event.

Table 1 Subject assessment of global efficacy relative to baseline $^{*}$

\begin{tabular}{|c|c|c|}
\hline Score & $\begin{array}{l}\text { Change from } \\
\text { baseline }\end{array}$ & Description \\
\hline 0 & Excellent & $\begin{array}{l}\text { Complete or almost complete relief of } \\
\text { ocular allergy symptoms }\end{array}$ \\
\hline 1 & Good & Distinct relief of ocular allergy symptoms \\
\hline 2 & & Some relief from ocular allergy symptom \\
\hline 3 & Poor & No relief from ocular allergy symptoms \\
\hline 4 & Deterioration & Worsening of ocular allergy symptoms \\
\hline
\end{tabular}

*The investigator assessment of global efficacy used this grading scale, except that ocular allergy signs were also part of the assessment. A score of 0 or 1 was used to define a responder.
Table 2 Assessment of individual symptoms and signs

\begin{tabular}{|c|c|}
\hline Score & Description \\
\hline \multicolumn{2}{|l|}{ Itching* } \\
\hline 0 & Absent \\
\hline 1 & $\begin{array}{l}\text { An intermittent tickle sensation involving more than } \\
\text { just the inner corner of the eye }\end{array}$ \\
\hline 2 & $\begin{array}{l}\text { A mild continuous itch (can be localised) not } \\
\text { requiring eye rubbing }\end{array}$ \\
\hline 3 & $\begin{array}{l}\text { A definite itch, the subject would like to be able to } \\
\text { rub eye }\end{array}$ \\
\hline 4 & $\begin{array}{l}\text { An incapacitating itch which would require } \\
\text { significant eye rubbing }\end{array}$ \\
\hline \multicolumn{2}{|l|}{ Tearing* } \\
\hline 0 & Absent \\
\hline 1 & Mild (eyes feel slightly watery) \\
\hline 2 & Moderate (occasional need to wipe eyes) \\
\hline 3 & Severe (tears rolling down cheeks) \\
\hline \multicolumn{2}{|r|}{ 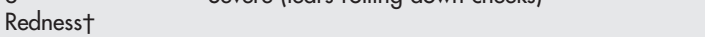 } \\
\hline 0 & Absent (vessels normal) \\
\hline 1 & Mild (some vessels definitely injected above normal) \\
\hline 2 & $\begin{array}{l}\text { Moderate (diffusely red eye with individual vessels } \\
\text { dilated but still discernible) }\end{array}$ \\
\hline 3 & $\begin{array}{l}\text { Severe (intensely red eye with intensive dilatation of } \\
\text { conjunctival vessels which are still but not easily } \\
\text { visible) }\end{array}$ \\
\hline \multicolumn{2}{|l|}{ Eyelid swelling $†$} \\
\hline 0 & Absent \\
\hline 1 & Mild (lids are a little puffy) \\
\hline 2 & Moderate (frank swelling of upper and lower lids) \\
\hline 3 & Severe (eyelids are swollen) \\
\hline \multicolumn{2}{|l|}{ Chemosis $†$} \\
\hline 0 & Absent or visually not detectable \\
\hline 1 & $\begin{array}{l}\text { Visually evident, raised conjunctiva especially at } \\
\text { limbal area }\end{array}$ \\
\hline 2 & Ballooning of conjunctiva \\
\hline
\end{tabular}

*Assessed by subject; †assessed by investigator.

\section{Statistical methods}

A sample size of 150 subjects was calculated to give a power of $80 \%$ to detect a treatment difference in the response rate as small as $16 \%$, at a significance level of $5 \%$ in a two sided test.

Treatment comparisons were made between ketotifen and placebo and between ketotifen and levocabastine. For analyses where the left and right eyes were evaluated separately, the eye with the highest itching score at baseline was selected. If the baseline values were the same for both eyes, the left eye was selected for analysis. The responder rates, and signs and symptoms were analysed using logistic regression for binary and ordinal data, respectively. Analyses included treatment as a main effect and were adjusted for baseline covariate and centre. A 5\% level of significance was used with two sided testing; no correction was made for multiple analyses.

Efficacy was analysed for the intent to treat (ITT) and the per protocol (PP) populations. Since results of the RAST involved a time factor, a subset of the ITT population was included for the analysis of efficacy to allow better interpretation of the data. This RAST positive, ITT population of subjects was considered to be the most appropriate group for evaluation of the primary efficacy variable because of their confirmed diagnosis of SAC. However, in medical practice, diagnosis of SAC is usually made without laboratory confirmation. Therefore, the ITT and the PP populations, which represent the most and least conservative approach, were also analysed. The ITT population was defined as all subjects who were randomised, received study medication, and had at least one post-baseline efficacy assessment. The PP population was defined as all subjects who completed the study without major deviations from the protocol procedures. Tolerability and safety were assessed for all subjects who received at least one dose of study medication. 


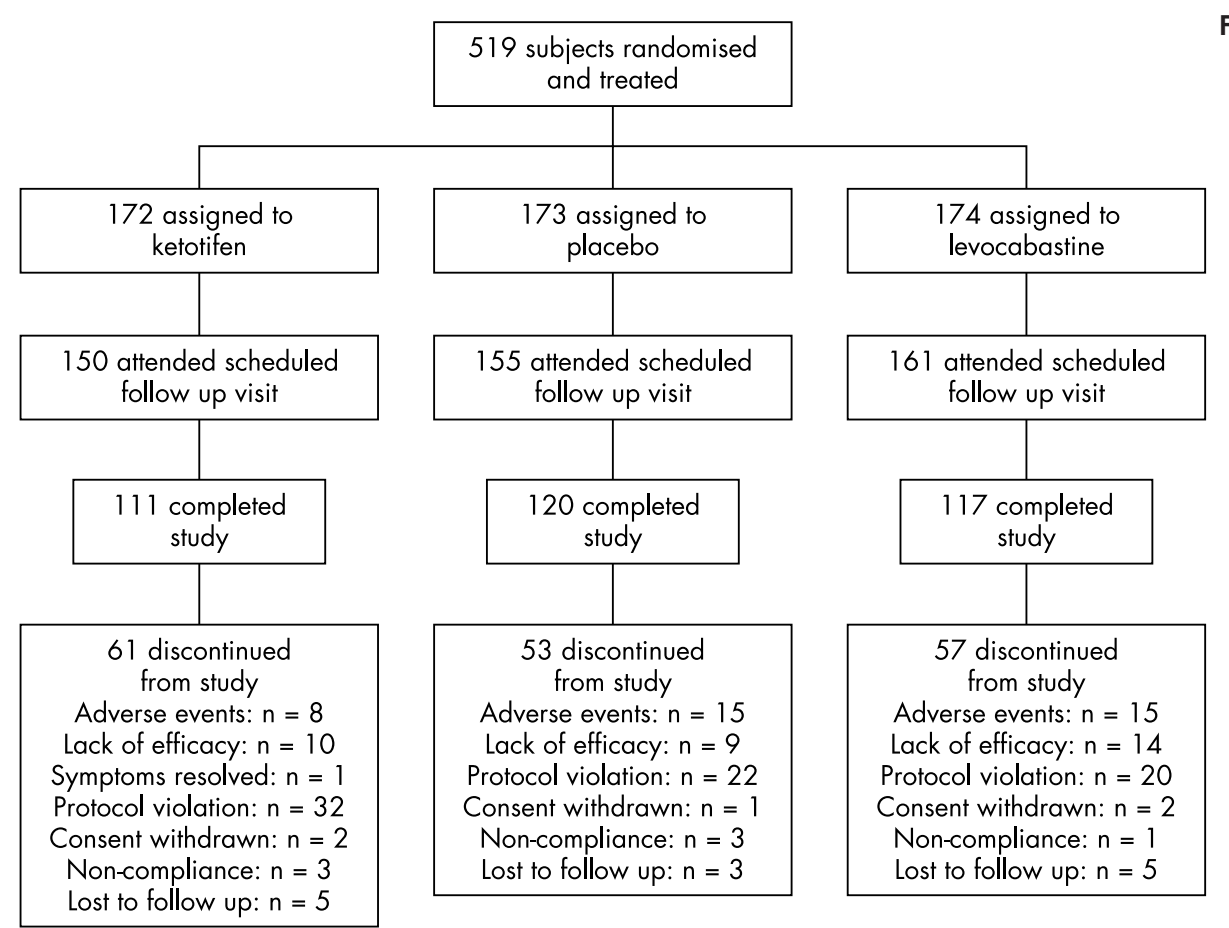

Figure 1 Profile of trial.

\section{RESULTS}

Of the 735 subjects screened, 519 were randomised and received treatment, 466 completed the follow up visit (days 5-8), and 348 completed the termination visit (days 25-31; Fig 1). Subject demographics (Table 3 ) and compliance with treatment (93.3-94.3\%) were similar across treatment groups.

\section{Responder rate and overall treatment response} Subjects' assessment

At the follow up visit, the responder rate, as judged by the subjects, was significantly greater with ketotifen compared with placebo in the RAST positive ITT population $(\mathrm{p}=0.02$; Table 4). The numerical superiority of ketotifen over placebo was confirmed in the PP population $(p=0.06)$. In the ITT population (including subjects with a negative or missing

\begin{tabular}{|c|c|c|c|}
\hline Characteristic & $\begin{array}{l}\text { Ketotifen } \\
\text { ( } n=172 \text { ) }\end{array}$ & $\begin{array}{l}\text { Placebo } \\
\text { (n= 173) }\end{array}$ & $\begin{array}{l}\text { Levocabastine } \\
(\mathrm{n}=174)\end{array}$ \\
\hline \multicolumn{4}{|l|}{ Sex, No (\%) } \\
\hline Male & 95 (55.2) & $82(47.4)$ & $88(50.6)$ \\
\hline Female & $77(44.8)$ & $91(52.6)$ & $86(49.4)$ \\
\hline \multicolumn{4}{|l|}{ Ethnic origin, No (\%) } \\
\hline European & $149(86.6)$ & $153(88.4)$ & $155(89.1)$ \\
\hline Pacific Islander & $3(1.7)$ & $2(1.2)$ & $2(1.1)$ \\
\hline Aboriginal & $1(0.6)$ & $0(0.0)$ & $1(0.6)$ \\
\hline Asian & $10(5.8)$ & $6(3.5)$ & $5(2.9)$ \\
\hline South East Asian & $5(2.9)$ & $4(2.3)$ & $7(4.0)$ \\
\hline Oriental & $1(0.6)$ & $2(1.2)$ & $5(1.0)$ \\
\hline Other & $3(1.7)$ & $6(3.5)$ & $2(1.1)$ \\
\hline \multicolumn{4}{|l|}{ Iris colour, No (\%) } \\
\hline Brown/hazel & $77(44.8)$ & $71(41.0)$ & $74(42.5)$ \\
\hline Green & 23 (13.5) & $17(9.8)$ & $16(9.2)$ \\
\hline Blue & $46(26.9)$ & $67(38.7)$ & $67(38.5)$ \\
\hline Grey & $12(7.0)$ & $13(7.5)$ & $9(5.2)$ \\
\hline Other & $13(7.6)$ & $5(2.9)$ & $8(4.6)$ \\
\hline Mean age (SD) (years) & $46.3(17.0)$ & $47.9(16.5)$ & 49.5 (17.4) \\
\hline
\end{tabular}

RAST), the relative odds favoured ketotifen compared with placebo but the difference was not significant (Table 4). The relative odds were in favour of ketotifen for the comparison with levocabastine across all the populations analysed, but the differences did not reach statistical significance. The overall treatment response, as judged by subjects at the follow up visit, for the RAST positive ITT population are shown in Figure 2A. The overall treatment response was statistically significant in favour of ketotifen versus placebo $(\mathrm{p}=0.005)$.

\section{Investigators' assessment}

At the follow up visit, the investigators' assessment of response to treatment showed that significantly more ketotifen treated subjects were judged as responders compared with the placebo group in the ITT $(p=0.02)$, RAST positive ITT $(\mathrm{p}=0.001)$, and the PP populations $(\mathrm{p}=0.005$; Table 4$)$. The overall treatment response at the follow up visit for the RAST positive ITT population, as judged by investigators is shown in Figure $2 \mathrm{~B}$ and was significantly in favour of ketotifen compared with placebo $(\mathrm{p}=0.003)$.

Although the investigator assessment of the ITT population approached significance in favour of ketotifen compared with levocabastine $(61.6 \%$ versus $51.7 \%$; $p=0.053)$, there were no significant differences in responder rates between ketotifen and placebo or ketotifen and levocabastine at the termination visit.

\section{Ocular signs and symptoms}

There were no significant differences between the treatment groups at baseline. At the follow up visit, the mean composite sign and symptom score for the ITT population was significantly in favour of ketotifen compared with both placebo and levocabastine (Table 5). Regarding individual ocular signs and symptoms, ketotifen was significantly superior to placebo and levocabastine in reducing tearing and redness (Table 5).

Based on subject diary records, the superiority of ketotifen in relieving signs and symptoms including itching, redness, 


\begin{tabular}{|c|c|c|c|c|}
\hline Analysis & Treatment group & \% Responders & Relative odds $\uparrow$ & $\mathrm{p}$ Valuet \\
\hline Subject assessment (RAST & Ketotifen $(n=109)$ & 49.5 & & \\
\hline \multirow{2}{*}{ positive ITT§) } & Placebo $(n=106)$ & 33.0 & 1.99 & 0.02 \\
\hline & Levocabastine $(n=107)$ & 41.1 & 1.43 & 0.20 \\
\hline Investigator assessment & Ketotifen $(n=109)$ & 53.2 & & \\
\hline \multirow{2}{*}{ (RAST positive ITT§) } & Placebo $(n=106)$ & 32.1 & 2.49 & 0.001 \\
\hline & Levocabastine $(n=107)$ & 45.8 & 1.39 & 0.24 \\
\hline \multirow[t]{3}{*}{ Subject assessment (ITT) } & Ketotifen $(n=163)$ & 47.9 & & \\
\hline & Placebo $(n=165)$ & 39.4 & 1.41 & 0.13 \\
\hline & Levocabastine $(n=166)$ & 38.6 & 1.46 & 0.09 \\
\hline \multirow[t]{3}{*}{ Investigator assessment (ITT) } & Ketotifen $(n=163)$ & 50.3 & & \\
\hline & Placebo $(n=165)$ & 38.2 & 1.66 & 0.02 \\
\hline & Levocabastine $(n=166)$ & 41.0 & 1.45 & 0.09 \\
\hline \multirow{3}{*}{ Subject assessment (PP) } & Ketotifen $(n=85)$ & 50.6 & & \\
\hline & Placebo $(n=78)$ & 35.9 & & \\
\hline & Levocabastine $(n=75)$ & 41.3 & 1.83 & 0.06 \\
\hline \multirow[t]{3}{*}{ Investigator assessment (PP) } & Ketotifen $(n=85)$ & 56.5 & 1.48 & 0.30 \\
\hline & Placebo $(n=78)$ & 34.6 & 2.51 & 0.005 \\
\hline & Levocabastine $(n=75)$ & 46.7 & 1.58 & 0.16 \\
\hline
\end{tabular}
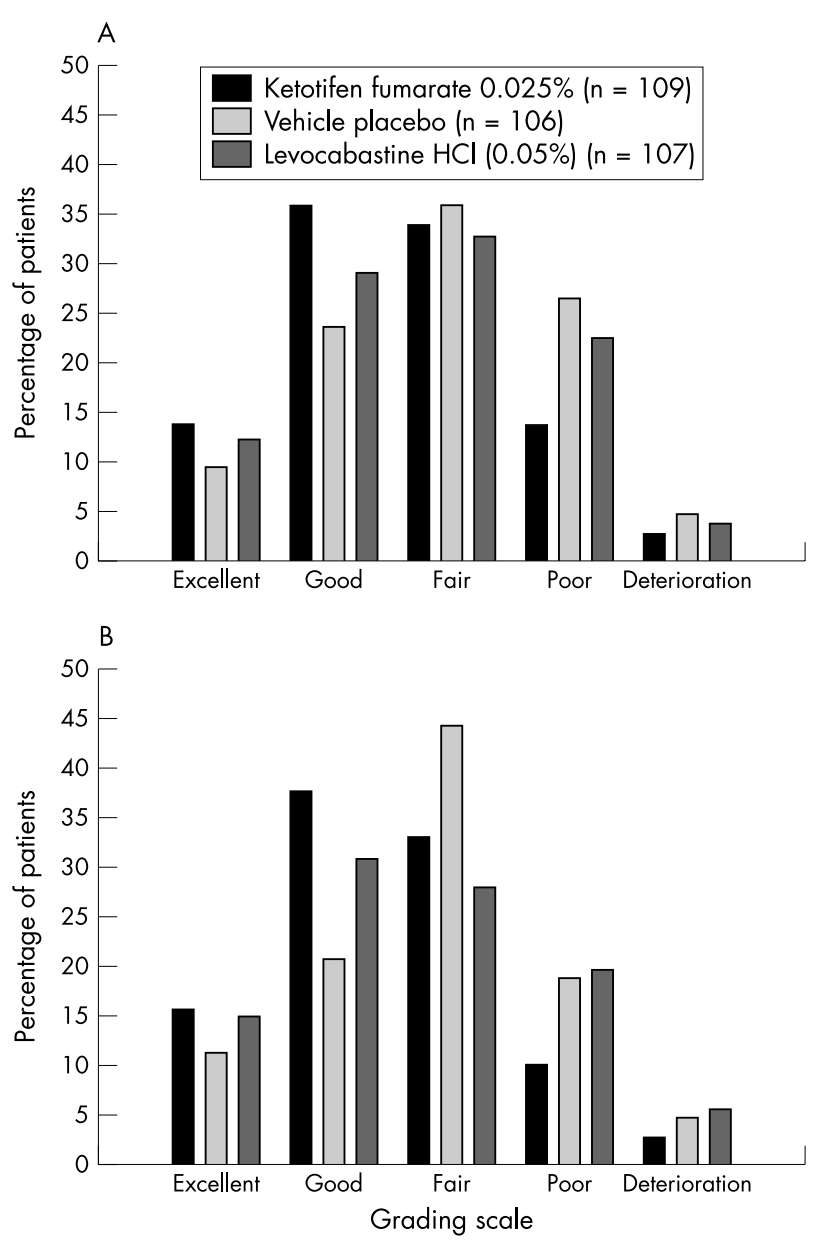

Figure 2 Overall treatment response at the follow up visit (days 5-8). Distribution (\%) of subjects by grading of global efficacy and treatment group in the radio-allergosorbent test positive intent to treat (RAST positive ITT) population for (A) subjects' assessment and (B) investigators' assessment. Based on logistic regression for ordinal data, the distribution of gradings was significantly in favour of ketotifen compared with placebo for each assessment $(p=0.005$ for subject and $p=0.003$ for investigator). and tearing was observed from the beginning of treatment and was most marked during the first 4 days (Fig 3). Mean scores for chemosis, eyelid swelling, and mucous discharge were generally low, and the between treatment differences were not significant. At the termination visit, the ITT analysis showed significantly better relief of signs and symptoms with ketotifen than with levocabastine, with mean composite sign and symptom scores of 2.56 and 3.34, respectively $(p=0.02)$.

Results from PP analyses were similar to those observed in the ITT population, with ketotifen consistently showing the best efficacy of all treatments.

\section{Symptom free days}

Throughout the study, the ITT analysis showed that the mean number of symptom free days was significantly higher with ketotifen compared with placebo (11.16 versus 8.67 days; $p=0.02)$. The mean number of symptom free days for levocabastine ( 10.34 days) was between that of placebo and ketotifen.

A very similar result was obtained from the PP analysis.

\section{Safety}

A total of 231 subjects reported 412 treatment emergent adverse events with or without a causal relation to the study medication, of which 80 were ocular and 332 were nonocular. All treatments were generally well tolerated; the type and frequency of adverse events were similar across treatment groups (Table 6), and the majority of adverse events $(76.7 \%)$ were of mild or moderate severity. However, the dropout rate due to adverse events was lower in the ketotifen group $(4.7 \% ; n=8)$ compared with placebo $(8.7 \% ; n=15)$ and levocabastine $(8.6 \% ; n=15)$. There were no significant differences between treatment groups in the incidence of individual ocular adverse events.

Four serious adverse events were recorded during the study, two ocular events in the placebo group (persistent photophobia and conjunctivitis with corneal ulcer) and two non-ocular events in the ketotifen group (hospitalisations due to abdominal pain and spontaneous pneumothorax, respectively). All four events were considered by the investigator to be unrelated to study medication.

\section{DISCUSSION}

In the target population of subjects with SAC confirmed by a diagnostic test (RAST positive ITT population), ketotifen was 
Table 5 Mean ocular signs and symptoms scores in the intent to treat population at day 5-8 visit

\begin{tabular}{|c|c|c|c|c|c|}
\hline \multirow[b]{2}{*}{$\begin{array}{l}\text { Signs and } \\
\text { symptoms }\end{array}$} & \multicolumn{3}{|c|}{ Mean score ${ }^{*}$} & \multicolumn{2}{|l|}{ p Valuet } \\
\hline & $\begin{array}{l}\text { Ketotifen } \\
(n=163)\end{array}$ & $\begin{array}{l}\text { Placebo } \\
(n=163)\end{array}$ & $\begin{array}{l}\text { Levocabastine } \\
(n=166)\end{array}$ & Ketotifen $v$ placebo & $\begin{array}{l}\text { Ketotifen } v \\
\text { levocabastine }\end{array}$ \\
\hline Redness & 0.80 & 0.93 & 0.92 & 0.03 & 0.04 \\
\hline Itching & 1.29 & 1.37 & 1.43 & 0.57 & 0.26 \\
\hline Tearing & 0.64 & 0.84 & 0.89 & 0.02 & 0.02 \\
\hline Chemosis & 0.26 & 0.34 & 0.30 & 0.10 & 0.32 \\
\hline Lid swelling & 0.40 & 0.51 & 0.45 & 0.22 & 0.84 \\
\hline Discharge & 0.16 & 0.23 & 0.20 & 0.11 & 0.20 \\
\hline $\begin{array}{l}\text { Composite } \\
\text { score }\end{array}$ & 3.54 & 4.15 & 4.18 & 0.03 & 0.03 \\
\hline
\end{tabular}

significantly superior to placebo in the subjects' assessment of global efficacy. This was confirmed by the investigators' assessment, showing significantly better treatment responses and higher responder rates with ketotifen than with placebo in all populations analysed. In addition, ocular sign and symptom scores consistently favoured the ketotifen group when compared with the placebo and levocabastine groups.

SAC improves over time regardless of treatment and acute episodes may last only a few days. Therefore, the primary time point for the assessment of efficacy was chosen to occur between days 5 and 8 of treatment. From treatment start to this visit, the benefits of ketotifen were most evident. The less marked between treatment differences observed at the termination visit (days 25-31), particularly for the responder rate, are consistent with the short duration of SAC episodes.

Fewer subjects discontinued because of adverse events with ketotifen than with placebo or levocabastine. Ketotifen was safe and well tolerated, with an ocular and non-ocular adverse event profile similar to the placebo group.

This environmental study provides important information regarding the efficacy, safety, and comfort of ketotifen eye drops in a clinical practice setting. The environmental study design has been used to evaluate the anti-allergy effects of several other ophthalmic formulations. ${ }^{7-9}$ However, this type of study is influenced by environmental factors ${ }^{10}$ such as variations in allergy season and weather conditions, high day to day variations in exposure to allergen, and high intersubject variability. In addition, a marked placebo effect of the vehicle eye drops may make it difficult to demonstrate a significant treatment benefit. To address some of the inherent problems in the design of environmental studies, both negative (placebo) and positive (levocabastine) controls were included for internal validation. In this particular study, compliance was excellent across all treatment groups and,
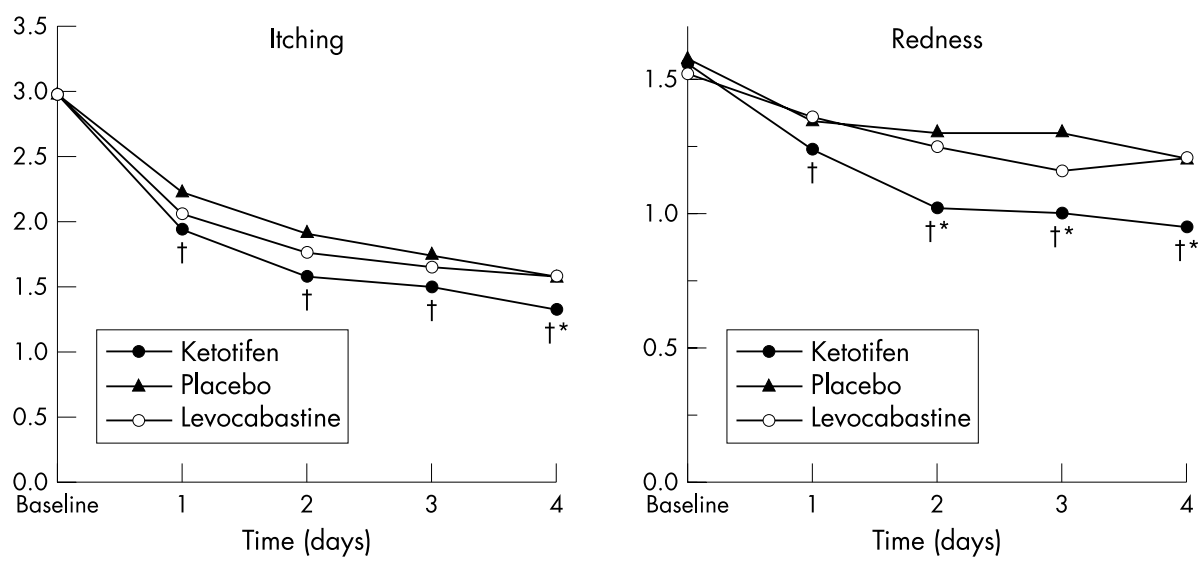

Figure 3 Subject diary mean scores for itching, redness, watery eyes, and overall symptoms within the first 4 days of treatment. Higher scores indicate more severe symptoms. $\mathrm{tp}<0.05 v$ placebo; ${ }^{*} p<0.05 v$ levocabastine.
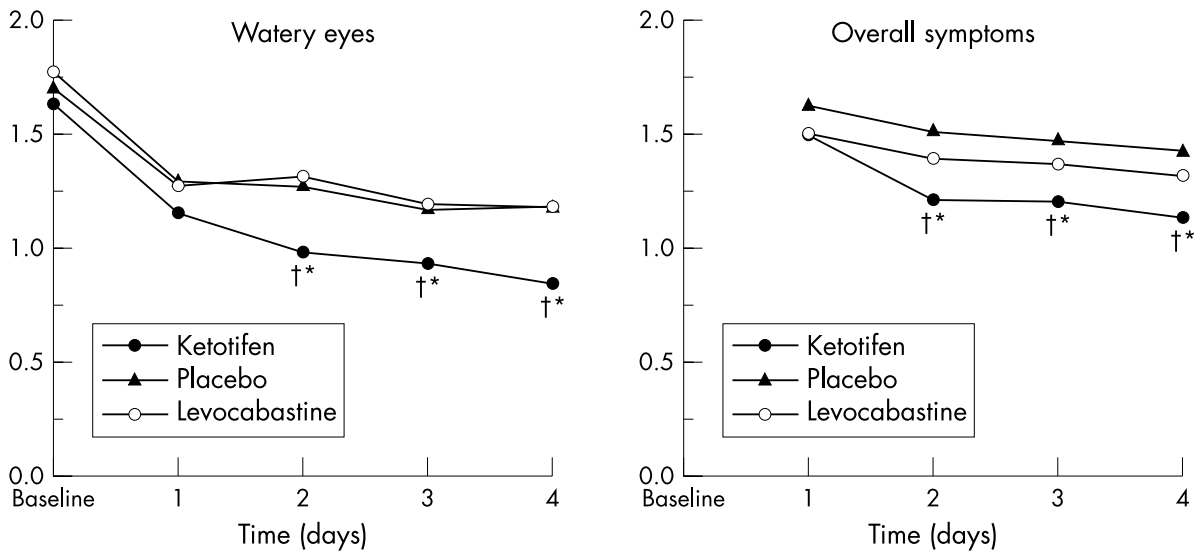
Table 6 Most frequently reported treatment emergent adverse events, regardless of causal relation to study medication. Values are numbers (\%) of subjects

\begin{tabular}{|c|c|c|c|}
\hline Adverse event & $\begin{array}{l}\text { Ketotifen } \\
\text { ( } n=172 \text { ) }\end{array}$ & $\begin{array}{l}\text { Placebo } \\
(n=173)\end{array}$ & $\begin{array}{l}\text { Levocabastine } \\
(n=174)\end{array}$ \\
\hline \multicolumn{4}{|l|}{ Ocular } \\
\hline Blurred vision & $2(1.2)$ & $3(1.7)$ & $2(1.1)$ \\
\hline Burning/stinging & $1(0.6)$ & $1(0.6)$ & $3(1.7)$ \\
\hline $\begin{array}{l}\text { Burning/stinging } \\
\text { upon instillation }\end{array}$ & $0(0.0)$ & $0(0.0)$ & $3(1.7)$ \\
\hline Conjunctivitis & $1(0.6)$ & $2(1.2)$ & $4(2.3)$ \\
\hline Eye pain & $2(1.2)$ & $3(1.7)$ & $2(1.1)$ \\
\hline Eyelid disorder & $2(1.2)$ & $4(2.3)$ & $1(0.6)$ \\
\hline Itching & $2(1.2)$ & $2(1.2)$ & $3(1.7)$ \\
\hline Dry eyes & $3(1.7)$ & $1(0.6)$ & $1(0.6)$ \\
\hline Photophobia & $2(1.2)$ & $2(1.2)$ & $1(0.6)$ \\
\hline \multicolumn{4}{|l|}{ Non-ocular } \\
\hline Headache & $28(16.3)$ & $28(16.2)$ & $25(14.4)$ \\
\hline Rhinitis & $9(5.2)$ & $6(3.5)$ & $10(5.7)$ \\
\hline Pharyngitis & $3(1.7)$ & $8(4.6)$ & $5(2.9)$ \\
\hline Allergic reactions & $3(1.7)$ & $6(3.5)$ & $2(1.1)$ \\
\hline Rash & $5(2.9)$ & $2(1.2)$ & $3(1.7)$ \\
\hline
\end{tabular}

importantly, the subject diaries were reliable and completed accurately.

Although the efficacy of ketotifen fumarate in SAC has already been shown in the conjunctival allergen challenge model, ${ }^{11}$ the findings of this study confirm that the effectiveness of ketotifen extends to the clinical setting. The therapeutic effects of ketotifen are thought to result from its multiple pharmacological mechanisms of action. Ketotifen is a drug that acts as a histamine $\mathrm{H}_{1}$ receptor antagonist and mast cell stabiliser. ${ }^{12}$ Further, ketotifen inhibits infiltration, activation, and degranulation of eosinophils ${ }^{13}$ and other late phase reactions, such as the effects of platelet activating factor. $^{14}$ The multiple actions of ketotifen may confer additional efficacy when compared with agents with a single anti-allergic mechanism. Thus, the ketotifen group exhibited a significantly better outcome than levocabastine for tearing, redness, and the composite score for ocular signs and symptoms. Also, the ketotifen group had a significantly higher number of symptom free days compared with the placebo group, indicating that, in addition to relieving the signs and symptoms of acute episodes of SAC, ketotifen can prevent recurrent attacks.

\section{CONCLUSION}

This study shows that in an environmental setting ketotifen fumarate $0.025 \%$ ophthalmic solution is effective in reducing the signs and symptoms of SAC, and in preventing their recurrence. Ketotifen consistently showed the best efficacy in comparison with both placebo and levocabastine. The favourable safety and tolerability profile of ketotifen may enhance compliance, leading to more effective control of the signs and symptoms of SAC.

\section{ACKNOWLEDGEMENTS}

This study was sponsored by Novartis Ophthalmics AG, Bülach, Switzerland. We thank Professor Hugh Taylor (Melbourne, Australia) for his input in the study protocol and the manuscript.

\section{PARTICIPATING CENTRES AND INVESTIGATORS}

The Royal Australian College of General Practitioners (RACGP): principal investigators: I Steven, S McKenzie (Griffith); investigators: B McGrath (Brisbane); C Hogan (Melbourne); J Garrood (Adelaide); T Quinlivan; V Keane (Perth): the University of Sydney, Department of General Practice: principal investigator: M Kidd (Sydney); investigators: C Cooper (Sydney); G Kelly (ACT); principal consultant ophthalmologist: H Taylor (Centre for Eye Research Australia, The University of Melbourne, Australia).

\section{Authors' affiliations}

M Kidd, C Cooper, The University of Sydney, Department of General Practice, Sydney, NSW, Australia

S H McKenzie, I Steven, Royal Australian College of General

Practitioners, Sydney, NSW, Australia

R Lanz, Novartis Ophthalmics AG, Bülach, Switzerland

*All participating Centres are listed at the end of the manuscript

Correspondence to: Professor Michael Kidd, The University of Sydney, Department of General Practice, Sydney, NSW, Australia; michael.kidd@med.usyd.edu.au

Accepted for publication 20 January 2003

\section{REFERENCES}

1 Weeke ER. Epidemiology of hay fever and perennial allergic rhinitis. Monogr Allergy 1987;21:1-20.

2 Abelson MB, George MA, Garofalo C. Differential diagnosis of ocular allergic disorders. Ann Allergy 1993:70:95-109.

3 Allansmith MR, Ross RN. Ocular allergy. Clin Allergy 1998;18:1-13.

4 Leonardi A. Pathophysiology of allergic conjunctivitis. Acta Ophthalmol Scand 1999;228(Suppl): $21-23$.

5 Leonardi A. Role of histamine in allergic conjunctivitis. Acta Ophthalmol Scand 2000;230(Suppl): 18-21.

6 Grant SM, Goa KL, Fitton A, et al. Ketotifen. A review of its pharmacodynamic and pharmacokinetic properties, and therapeutic use in asthma and allergic disorders. Drugs 1990:40:412-48.

7 Blumenthal MN, Schwartz RH, Kaiser H. Nedocromil sodium 2\% ophthalmic solution for the treatment of ragweed pollen seasonal allergic conjunctivitis. Ocul Immunol Inflamm 2000;8:159-67.

8 Donshik PC, Pearlman D, Pinnas J, et al. Efficacy and safety of ketorolac tromethamine $0.5 \%$ and levocabastine $0.05 \%$ a multicenter comparison in subjects with seasonal allergic conjunctivitis. Adv Ther 2000;17:94-102.

9 Giede C, Metzenauer P, Petzold U, et al. Comparison of azelastine eye drops with levocabastine eye drops in the treatment of seasonal allergic conjunctivitis. Curr Med Res Opin 2000;16:153-63.

10 Abelson MB. Comparison of the conjunctival allergen challenge model with the environmental model of allergic conjunctivitis. Acta Ophthalmol Scand 1999;228(Suppl):38-42.

11 Gomes PJ, Welch DL, Abelson MB. Evaluation of the efficacy and safety of ketotifen fumarate in the allergen challenge model [ARVO Abstract]. Invest Ophthalmol Vis Sci 2000;41:S926, [Abstract 4926.]

12 Abelson MB, Schaefer, K. Conjunctivitis of allergic origin: immunologic mechanisms and current approaches to therapy. Surv Ophthalmol 1993:38(Suppl):115-32.

13 Nabe M, Miyagawa H, Agrawal DK, et al. The effect of ketotifen on eosinophils as measured at LTC4 release and by chemotaxis. Allergy Proc 1991; 12:267-71.

14 Devillier P, Arnoux B, Lalau KC, et al. Inhibition of human and rabbit platelet activation by ketotifen. Fundam Clin Pharmacol 1990;4:1-9. 